\title{
Functional Dependencies and Indirect Binding
}

\author{
Yael Sharvit \\ Rutgers University
}

The functional analysis of wh-expressions (Engdahl (1986), Groenendijk \& Stokhof (1984), Chierchia $(1991,1993)$ ) provides a basis for explaining cases of Indirect Binding, where a quantified expression inside a relative clause triggers a bound interpretation of a variable which is outside its s-structure scope. I show that in these cases the variable is not bound by the quantified expression itself, and argue that Indirect Binding in copular vs. non-copular sentences mirrors the distinction between functional vs. pair-list questions.

\section{The Problem of Indirect Binding}

It is observed in Doron (1982) that in Hebrew, a quantified expression in a relative clause (RC) can bind a pronoun outside its scope. This is exemplified in (1), where oto ('him') can be interpreted as bound by kol gever ('every man'), in which case each man is paired with a different woman:

$$
\begin{aligned}
& \text { [ha-iSa } \quad \mathrm{Op}_{\mathrm{j}} \mathrm{Se} \text { kol gever pagaS } \mathrm{t}_{\mathrm{j}} \text { ] hizmina oto } \\
& \text { the-woman that every man met invited him }
\end{aligned}
$$

'The woman every man met invited him'

A similar phenomenon in English copular sentences is discussed in Hornstein (1984) and Jacobson (1994) among others, and is exemplified in (2):

(2) [The woman Op, every man invited $t_{\text {, }}$ to the party] was his mother.

Jacobson (1994) proposes an analysis of (2), which assumes a cross-categorial analysis of the copula, and a cross-categorial analysis of the definite determiner (see also von Stechow (1990)). According to this proposal, the pre-copular DP in (2) is interpreted as the unique function which maps men to the women they invited to the party, and the post-copular DP is interpreted as the 'mother-of' function. The sentence asserts that the two functions are the same.

Given (1), it is evident that a more general theory of Indirect Binding is needed, namely, one which does not treat this kind of binding as a special property of copular sentences. It is worth noting, in this connection, that the phenomenon extends beyond copular sentences even in English. This is shown in (3), where himself and him are interpreted as bound by every candidate:

(3) [The picture of himself which every candidate liked] made him famous. 
Note that Indirect Binding does not depend on the presence of a pronoun in the matrix VP. A complex DP (which embeds an RC) may get a "multipleindividual" reading, even if it does not c-command any overt pronoun outside it. This is illustrated in the Hebrew (4) and (5) (but can be shown for English too), where each man may be paired with a different woman:

$$
\begin{array}{lllll}
\text { [ha-iSa } & \text { Se } & \text { kol gever pagaS] nexmada } & \text { me'od } \\
\text { the-woman } & \text { that } & \text { every } & \text { man met nice } & \text { very }
\end{array}
$$
'The woman every man met is very nice'

$\begin{array}{lllllll}\text { dibarti } & \text { im } & \text { [ha-iSa } & \text { Se } & \text { kol } & \text { gever } & \text { pagaS] } \\ \text { I-talked } & \text { with } & \text { the-woman } & \text { that } & \text { every } & \text { man } & \text { met }\end{array}$

An adequate theory of Indirect Binding should capture this fact.

This paper proposes a uniform analysis of Indirect Binding which relies on the cross-categorial analysis of the, and predicts Indirect Binding to occur whenever a functional dependency is licensed in an RC. In that sense, copular and "verbal" sentences alike license Indirect Binding. ${ }^{1}$ Although both constructions involve functional dependencies, I argue that only copular sentences involve "natural" functions (in the sense of Engdahl (1986) and Chierchia (1993)). Roughly speaking, a "natural" function is an intensional function whose name is expressible in natural language (e.g., mother), whereas a "non-natural" (or "pairlist") function is a set of arbitrary pairs. Verbal Indirect Binding involves functions of the latter kind. One observation which this distinction aims to capture is illustrated by the contrast between (1) and (6):

ha-iSa Se kol gever pagaS hayta ima Selo
the-woman that every man met was mother his
'The woman every man met was his mother'

Despite the fact that in (6), woman is preceded by the definite article, the sentence can be acceptable in a situation where some man or other met some other woman in addition to his mother (the same effect is noted in Jacobson (1994) for English copular sentences). On the other hand, the verbal sentence in (1) can be true only if each man met exactly one woman. A similar contrast between functional and pair-list questions is discussed in Groenendijk \& Stokhof (1984).

The intuition behind the proposed analysis is that in (1) we check whether each man is paired with exactly one woman, whereas in (6) we check whether the relation within the pairs is of the right kind. I will show that this difference follows from the distinction between "natural" functions and "pair-list" functions, and from the assumption that they differ from each other in the way their domains are fixed. This is also the position taken in Chierchia (1993) and Dayal (1996) with respect to the distinction between functional and pair-list wh-questions.

My analysis is based on the view that functional wh-expressions in $\mathrm{A}^{\prime}$ positions have functional traces (i.e., traces which are translated as $f(x)$, where $f$ 
is a function from individuals to individuals). I argue that in a verbal sentence, a DP which contains a functional dependency is interpreted as a set of relations from individuals to $<e, e>$-type functions, and its sister is interpreted as a relation of this type. In a copular sentence, a DP which contains a functional dependency is interpreted as a unique function from individuals to individuals (essentially as in Jacobson (1994)). This analysis predicts a "multiple-individual" reading for verbal and copular sentences without giving the quantifier "long distance" scope.

The analysis also predicts certain scope interactions in constructions of this type, in addition to the subject/object asymmetry which is characteristic of RC's. But before turning to the details of the analysis and its predictions, let us show that an alternative analysis based on scoping (such as Quantifier Raising) cannot be appealed to.

\section{Ruling out “long” Quantifier Raising (QR)}

It is usually assumed that $\mathrm{QR}$ is clause-bounded, an assumption which is not uncontroversial (see, for example, Farkas and Giannakidou, (1996)). If QR respects clause-boundedness, then an analysis of, say, (3) along the lines of (7) is not possible, since every man is QR-ed "long distance":

(7) a. [every candidate $]_{i}\left[\right.$ [the picture of himsel $f_{i}$ that $t_{i}$ liked $]$ made him famous]

b. $\forall \mathrm{x}$ [candidate' $(\mathrm{x}) \rightarrow$ the picture of $\mathrm{x}$ that $\mathrm{x}$ liked made $\mathrm{x}$ famous]

Given that the clause-boundedness of $\mathrm{QR}$ has been questioned (due to apparent violations of it), one could ask whether Indirect Binding is just another instance of clause-boundedness violation. I argue, however, that in the Indirect Binding cases, "long distance” QR gives rise to several wrong predictions.

\section{I The Subject/Object Asymmetry}

The following observation is inconsistent with a "long distance" $Q R$ analysis of Indirect Binding: If the trace of the relative operator in an $\mathrm{RC}$ is not in the scope of the quantified expression, the bound (or "multiple-individual") reading is not available. This is observed in Hornstein (1984) for copular sentences (as demonstrated by the contrast between (8) and (9)), but it is also true for verbal sentences (as shown by the contrast between (10) and (11)):

(8) The woman who ${ }_{j}$ every man invited $t_{j}$ was his mother.

(9) The woman who, $t_{j}$ invited every man was his mother.

(10) [Those friends of his [who ${ }_{j}$ every politician supported $t_{j}$ ] voted for him. 
(8) and (10), where the trace of the relative operator is in the scope of every man and every politician respectively, have a "multiple-individual" reading, where the pronoun in the matrix VP is interpreted as bound. (9) and (11), on the other hand, where the trace of the relative operator is not in the scope of every man and every politician respectively, allow only for a "single-individual" reading, where the pronouns are interpreted as free variables.

The argument against $\mathrm{QR}$ goes like this: If $\mathrm{QR}$ is possible in (8) and (10), it should be possible in (9) and (11) too. But it is precisely cases like (9) and (11) which have led to the conclusion (e.g., Cooper (1978)) that scoping out of an RC is impossible (presumably because of a violation of the Complex-NP Constraint). Copular sentences (which do allow Indirect Binding), have been considered to be exceptional, requiring an exceptional treatment. Examples such as (1), (3) and (10), show that this is not the case. Apart from Doron's (1982) discussion of the Hebrew facts, however, Indirect Binding in verbal constructions has been ignored. Perhaps what clouds the issue is the fact that in the English verbal case, the relative head must contain an anaphor or a pronoun for the sentence to have a bound reading. However, Indirect Binding is not a strictly "copular" phenomenon.

To sum up, the correct generalization about Indirect Binding is the following: it is generally possible for a DP which contains an RC to receive a "multiple-individual" reading, both in copular and verbal constructions, if the trace of the relative operator is in the scope of a quantified expression. Languages may differ with respect to what facilitates such readings (as the contrast between the Hebrew (1) and the English (3) indicates), but it is clear that QR is not a plausible analysis of these cases.

\subsection{The Clause-boundedness of $Q R$}

The clause-boundedness of $\mathrm{QR}$ in cases such as (12), where every professor cannot have matrix scope, is mimicked by the Indirect Binding cases as in (13) and (14):

(12) Someone thinks that every professor likes to praise himself.

(13) Some kid thinks that the woman who every man invited was his mother.

(14) Some woman thinks that the picture of himself that every man hates will be given to her.

In (13) and (14), although every man is interpreted as having scope over the embedded clause, it does not have matrix scope. But this is precisely what a QR analysis of Indirect Binding predicts: if scoping of every man out of the embedded clause is allowed in principle, there is no reason why it should not have matrix scope, but it doesn't: 
(15) *[every man $]_{\mathrm{i}}[\text { [some kid }]_{\mathrm{j}}\left[\mathrm{t}_{\mathrm{j}}\right.$ thinks that the woman $\mathrm{t}_{\mathrm{i}}$ invited was ...]

(16) $\forall \mathrm{x}$ [man' $(\mathrm{x}) \rightarrow \exists \mathrm{y}\left(\mathrm{kid}^{\prime}(\mathrm{y}) \& \mathrm{y}\right.$ thinks the woman $\mathrm{x}$ invited was $\mathrm{x}$ 's mother)]

(17) * [every man $]_{\mathrm{i}}$ [some woman $]_{\mathrm{j}}\left[\mathrm{t}_{\mathrm{j}}\right.$ thinks that the picture of $\mathrm{t}_{\mathrm{i}} \ldots .$. ]

(18) $\forall \mathrm{x}\left[\right.$ man' $^{\prime}(\mathrm{x}) \rightarrow \exists \mathrm{y}($ woman' $(\mathrm{y}) \& \mathrm{y}$ thinks that the picture of $\mathrm{x}$ that $\mathrm{x}$ hates will be given to $\mathrm{y})]$

(13) does not have the interpretation in (16), where the choice of women varies with men. Similarly, (14) does not have the interpretation in (18).

The fact that every man does not have matrix scope in (13) and (14) suggests that its scope is limited to the minimal clause which contains the complex DP, and it is the complex DP itself which respects clause-boundedness. And indeed, as will be shown, this is what the functional analysis predicts.

\subsection{QR and Decreasing Quantifiers}

When the subject of the RC is a no-NP type quantified expression, a "long distance" $\mathrm{QR}$ analysis does not give rise to the right truth conditions. This has been observed in Dahl (1981) for RC's in copular sentences, and is illustrated below:

(19) The woman no man invited was his mother.

(20) * [no man $]_{i}$ [the woman $t_{i}$ invited...]

(21) $\forall \mathrm{x}\left(\right.$ man' $^{\prime}(\mathrm{x}) \rightarrow \neg$ the woman $\mathrm{x}$ invited was $\mathrm{x}$ 's mother $)$

(19) does not have the reading in (21), as the "long" QR analysis in (20) predicts. Suppose John invited Mary and his mother, but did not invite Sally. According to our intuitions, (19) is false, but according to (21), it comes out true. Since there is no unique woman such that John invited her, "the woman John invited was his mother" is false, and its negation is true. The reason $Q R$ yields the wrong interpretation is that by scoping no man out, the negative operator is assigned sentential scope, which, in fact, it does not have.

\section{Relative Clauses, WH-Questions, and Weak Crossover (WCO)}

Having shown that a scoping analysis cannot be appealed to in order to account for Indirect Binding, let us turn to the functional analysis, which is inspired by the functional analysis of wh-questions (Engdhal (1986), Groenendijk \& Stokhof (1984), Chierchia (1991, 1993), Dayal (1996), Bittner (to appear) and others).

RC's pattern together with wh-questions with respect to some of the issues mentioned above. For example, as is well known, wh-questions exhibit a subject/object asymmetry which is demonstrated by the contrast between (22) and (23): (22), where the trace of which woman is in the scope of every man, licenses 
either a functional answer (according to which every man loves his own mother) or a pair-list answer; but (23), where the trace of which woman is not in the scope of every man does not license either answer:

(22) Q: Which woman ${ }_{j}$ does every man love $t_{j}$ ?

A: a. His mother.

b. John, Mary; Bill, Sally...

Q: Which woman $_{j} t_{j}$ loves every man?

A: a. *His mother.

b. *Mary, John; Sally, Bill...

In addition, wh-questions also resist a scoping analysis (especially with decreasing quantifiers). This is illustrated in (24), which has neither the interpretation in (25) (with the negative operator taking matrix scope), nor the one in (26) (with the negative operator taking scope over the embedded question), as pointed out in Engdahl (1986):

(24) John wonders what no married man should forget.

(25) a. * *no married man $]_{i}$ [John wonders what $t_{i}$ should forget]

b. $\quad \forall x\left(\right.$ married-man' $(x) \rightarrow \neg w^{\prime} \operatorname{wder}^{\prime}\left(\lambda \mathrm{p} \exists y\left[p={ }^{\wedge}\right.\right.$ forget $\left.\left.\left.^{\prime}(y)(x)\right]\right)(j)\right)$

a. $\quad * J o h n$ wonders [[no married man $]_{i}\left[\right.$ what $t_{i}$ should forget ]]

b. $\quad$ wonder' $\left(\lambda p \forall x\left(\right.\right.$ married-man' $(x) \rightarrow \neg \exists y\left[p={ }^{\wedge}\right.$ forget' $\left.\left.\left.^{\prime}(y)(x)\right]\right)\right)(j)$

The problem with (25) is that it means that for every married man, John does not wonder what he should forget. The problem with (26) is that the complement set of wonder admits false propositions. However, both (25) and (26) should be possible if a scoping analysis is pursued (see Engdahl (1986) for further discussion of the problem).

As shown by various proponents of the functional approach to whquestions, many of the scope problems which arise with the QR approach are solved by the functional analysis. According to this view, the existential quantifier associated with the wh-phrase in (22) and (24) binds a function variable (of type $\langle e, e\rangle$ ) instead of an individual variable, thus allowing the quantified expression to be interpreted in the clause where it originates. So, for example, in (24), no married man is interpreted in its own clause, and negation has scope over that clause, as it should ("John wonders what is the function which maps married men to what they shouldn't forget"):

$$
\text { wonder }{ }^{\prime}\left(\lambda p \exists f l p=` \forall x\left(\text { married-man' }(x) \rightarrow \neg f^{\prime} \operatorname{orget}^{\prime}(f(x))(x)\right) \mid\right)(j)
$$

According to most theories of functional questions, the source of the functional interpretation is the trace (or gap) created by the movement of the whphrase to a pre-sentential position (e.g., Spec,CP). Theories differ with respect to how this interpretation comes about. Here I adopt Chierchia's $(1991,1993)$ 
proposal, according to which the interpretation of the wh-trace as $f(x)$ is read off directly from the syntax of the trace. The trace itself carries two indices, a function index (a subscript, which stands for the function variable), and an argument index (a superscript, which stands for the argument variable): [ $\left.t_{j}{ }_{j}\right]$. Furthermore, Chierchia argues that the argument variable is a pronominal element. This pronominal element exhibits the behavior characteristic of pronouns - specifically, WCO effects. The subject/object asymmetry, according to this view, is accounted for in WCO terms: ${ }^{2}$ in the grammatical (28), raising of every man does not involve "crossing over" a functional trace, whereas in the ungrammatical (29) it does:

(28) Which woman ${ }_{j}$ does [[every man $]_{i}\left[t_{i}\right.$ love $\left.\left.t_{j}^{i}\right]\right]$

(29) Which woman $_{j}[\text { [every man }]_{i}\left[t_{j}{ }^{i}\right.$ loves $\left.\left.t_{i}\right]\right]$

The only grammatical reading of (29), then, is one where the trace of which woman is not multiply-indexed, and therefore the only possible answer is an individual denoting expression.

Assuming that any wh-trace, and in particular, the trace of a relative operator, can be functional, we can account for the subject/object asymmetry in RC's as a WCO effect too. For example, (30) does not involve crossing over a functional trace, whereas $(31)$ does: $^{3}$

(30) The woman $\left[O \mathrm{p}_{\mathrm{j}}[\text { [every man }]_{\mathrm{i}}\left[\mathrm{t}_{\mathrm{i}}\right.\right.$ chose $\left.\left.\left.\mathrm{t}_{j}^{\mathrm{i}}\right]\right]\right]$

(31) The woman $\left[O p_{j}\left[[\text { every man }]_{i}\left[t_{j}{ }^{i}\right.\right.\right.$ chose $\left.\left.\left.t_{i}\right]\right]\right]$

This account predicts the subject/object asymmetry in copular as well as verbal sentences, and in fact provides strong evidence that both these constructions involve functional dependencies. Having established that, we can now show how this approach predicts Indirect Binding.

\section{The Functional Analysis of Indirect Binding}

In sections 2 and 3 we saw why a functional approach to RC's and wh-questions is superior to the scoping approach, based on its account of the subject/object asymmetry characteristic of these constructions, and based on some wrong scope predictions made by the QR analysis. I now show that the similarity between RC's and questions goes beyond the predictions made by $\mathrm{QR}$. The distinction between copular and verbal sentences with Indirect Binding, I argue, mirrors the distinction between functional and pair-list questions.

\subsection{The Copular/Verbal Distinction}

As observed in Groenendijk \& Stokhof (1984), his mother is a possible answer to 
which woman does every man love, even if some man or other loves another woman in addition to his mother. A list answer (such as John loves Sally and Bill loves Mary) is not possible in such a situation (even if Sally happens to be John's mother and Mary happens to be Bill's mother). Copular sentences pattern together with functional questions, and verbal sentences pattern together with pair-list questions in this respect. Consider again the contrast between (1) and (6) in section 1 . The latter can be true in a situation where some man or other met his mother and some other woman, but the former cannot.

In addition, functional questions admit a wide range of quantified expressions in the position which c-commands the functional trace, whereas pairlist questions are much more restricted. This is illustrated by the contrast between (22) (section 3) and (32):
Which woman does no man love $t_{j}{ }_{j}$ ?
a. His mother.
b. *John, Mary; Bill, Sally.

Copular and verbal sentences contrast with each other in a similar way, as shown by the following examples:

(33) The picture of himself which no candidate sent on time was his driver's license photo.

(34) ??The picture of himself which no candidate sent on time was sent back to him.

As argued in Chierchia (1993) for the question case, the main difference between "purely" functional questions and pair-list questions is that in the former, the domain of the function is determined pragmatically, whereas in the latter, the domain of the function is specified. For example, the representation of the pair-list reading of which woman does every man love (as opposed to the representation of its functional reading), specifies that the domain of the function is the set of men. This is done by extracting a minimal witness set from the quantifier which ccommands the functional trace, thus guaranteeing that the pair-list answer is an exhaustive list. ${ }^{4}$ Chierchia proposes an absorption mechanism which yields this result. Dayal (1996), capitalizing on Chierchia's idea, proposes that the distinction between functions with a specified domain and "natural" functions is built into the wh-complementizer, which is ambiguous between two readings.

I propose that verbal Indirect Binding involves quantification over "extensional" functions (i.e., sets arbitrary of pairs), whereas copular Indirect Binding involves quantification over "natural" functions. This ambiguity is built into the relative operator, which is ambiguous between the following two readings (where $\mathrm{P}$ is of type $\langle\mathrm{e}, \mathrm{t}\rangle, \mathrm{K}$ is of type $\langle\mathrm{e},\langle\langle\mathrm{e}, \mathrm{e}\rangle, \mathrm{t}\rangle\rangle, \mathrm{F}$ is of type $\langle\langle e, e\rangle, t\rangle$, and $f$ is of type $\langle e, e\rangle$ ): 


\section{a. $\quad \lambda P \lambda \operatorname{K} \lambda f[\operatorname{Dom}(\mathrm{f})=\mathrm{P} \& \forall \mathrm{x}(\mathrm{x} \in \operatorname{Dom}(\mathrm{f}) \rightarrow \mathrm{K}(\mathrm{x})(\mathrm{f}))]$ \\ b. $\quad \lambda \mp \lambda \mathrm{f}[\mathrm{f} \in \mathfrak{\Im} \& \mathbb{F}(\mathrm{f})]$}

Both expressions ultimately yield sets of functions: (35a) yields a set of functions with a specified domain, as opposed to (35b), which yields a set of functions which are members of the set $\$$ of contextually relevant "natural" functions.

If (35a) is used, then the value of $P$ must be fixed in some way. I assume (following Dayal (1996)) that it is fixed by extracting a unique minimal witness set from the quantified expression which c-commands the trace of the relative operator. ${ }^{5}$ So, for example, the unique minimal witness set of every man is the set of men. By adjoining every man to the relative operator, we can combine the meaning of the relative operator with the derived meaning of every man (i.e., its unique minimal witness set). The adjunction of every man to the relative operator results in double-indexing of the relative operator and of the DP which contains it (see Haïk (1984) and Shlonsky (1987) for similar proposals). The containing DP itself has the option of being QR-ed, in which case it leaves behind a trace which carries copies of all the indices of its antecedent.

If (35b) is used, then the subject of the RC undergoes standard QR. The two possible LF's are given in (36):

(36)

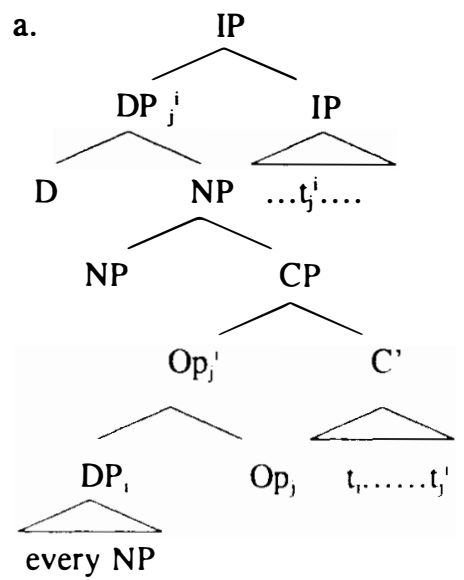

b.
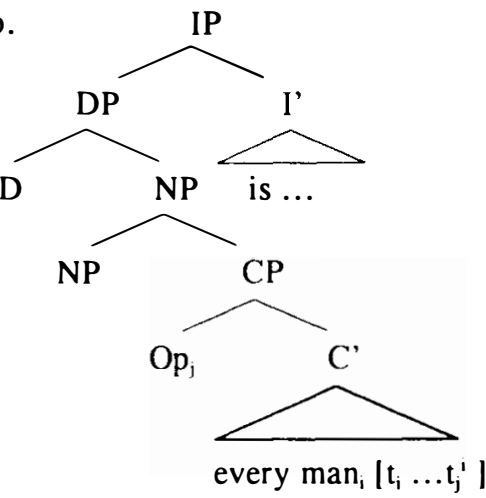

(36a) represents a sentence with an $\mathrm{RC}$ whose relative operator is translated as the expression in (35a) - an expression which requires a variable of type $\langle e, t\rangle$. (36b) represents a sentence with an RC whose relative operator is translated as the expression in (35b). As it turns out, (36a) is the structure of verbal Indirect Binding (where the subject of the RC undergoes non-standard QR), and (36b) is the structure of copular Indirect Binding (where the subject of the RC undergoes standard QR).

As for the semantics, I assume, in the spirit of Engdahl (1986), that a +wh phrase can be interpreted as a set of functions, using a rule of Closure. A relative 
head is +wh by virtue of being co-indexed with the relative operator. Accordingly, the translation of, say, the relative head [woman] is $\lambda f[\forall x(x \in \operatorname{Dom}(f) \rightarrow$ woman'(f(x)))]), and that of [picture of himself] is $\lambda f[\forall x(x \in \operatorname{Dom}(f) \rightarrow$ pictureof' $(x)(f(x)))]$.

In addition, following Jacobson (1994) (see also Sharvit (1996) and Bittner (1996)), I assume that the is cross-categorial. That is to say, it may pick out a unique entity of any type. The translation of functional the is given in (37) (where $\mathbf{F}$ is a property of functions):

\section{$\lambda F \sigma f[f(f)]$}

$\sigma f[f(f)]$ is the maximal function with the property $F$. The definition of $\sigma[f(f(f)]$ (based on Link's (1983) theory of plurals), is given in (38):

$$
\sigma f[F(f)]=\operatorname{tf}[f(f) \& \forall g[F(g) \rightarrow g s f]]
$$

According to (38), of $[\mathbf{F ( f ) ] ~ i s ~ t h e ~ u n i q u e ~ f u n c t i o n ~} f$ with the property $\mathbf{F}$ such that all other functions with the same property stand in the 'part of' relation to $f$. The 'part of' relation is defined for $<\mathrm{e}, \mathrm{e}>$-type functions in (39):

$$
f \leq g \text { iff } \forall x[f(x) \leq g(x)]
$$

According to (38) and (39), the maximal function with the property $F$ is the function which yields the maximal output for every $\mathrm{x}$ in its domain.

\subsection{Indirect Binding in Verbal Sentences}

In a verbal sentence with Indirect Binding (which corresponds to the LF in (36a)), the complex DP is interpreted as a set of relations between individuals and $<e, e>$-type functions (similar to Dayal's analysis of Hindi correlatives). The sister of this DP is interpreted as a relation between individuals and $<\mathrm{e}, \mathrm{e}>$-type functions. This analysis makes crucial use of functional the and of the following type-shifting operator, which turns an expression of type $\langle e, e\rangle$ into a set of relations of type $\langle e,\langle<e, e\rangle, t\rangle>$ :

$$
\lambda g \lambda K \exists f[f=g \& \forall x(x \in \operatorname{Dom}(f) \rightarrow K(x)(f))]
$$

(40) provides the universal quantifier which does the "job" of Indirect Binding. The structure and interpretation of (1) are given in (41) and (42) respectively: 
(41)

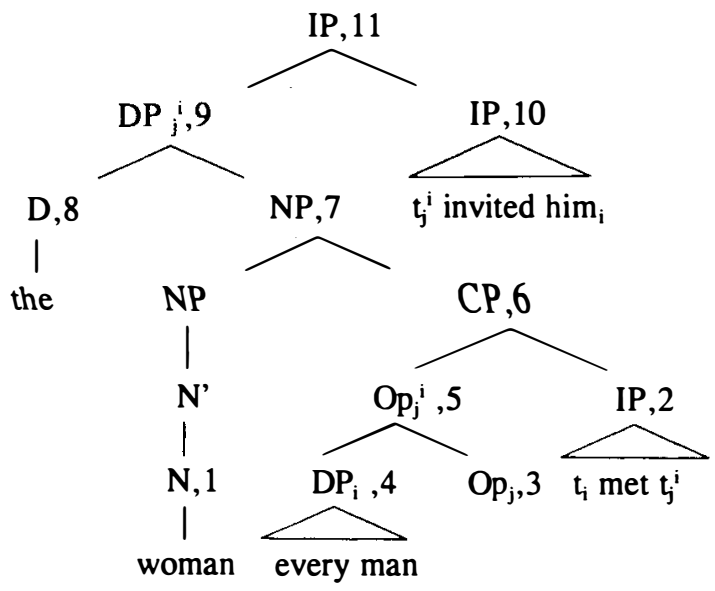

(42) 1. $\lambda f\left[\forall x\left(x \in \operatorname{Dom}(f) \rightarrow\right.\right.$ woman' $\left.\left.^{\prime}(\mathrm{f}(\mathrm{x}))\right)\right]$

2. $\lambda x \lambda f[$ meet' $(\mathrm{f}(\mathrm{x}))(\mathrm{x})]$

3. $\lambda P \lambda K \lambda f[\operatorname{Dom}(f)=P \& \forall x(x \in \operatorname{Dom}(f) \rightarrow K(x)(f))]$

4. $\quad \mathrm{lW}\left(\lambda \mathrm{P}\left[\forall \mathrm{x}\left(\operatorname{man}{ }^{\prime}(\mathrm{x}) \rightarrow \mathrm{P}(\mathrm{x})\right)\right]\right)$

4'. man'

5. $\lambda \mathrm{K} \lambda \mathrm{f}[\operatorname{Dom}(\mathrm{f})=$ man' $\& \forall \mathrm{x}(\mathrm{x} \in \operatorname{Dom}(\mathrm{f}) \rightarrow \mathrm{K}(\mathrm{x})(\mathrm{f}))]$

6. $\lambda \mathrm{f}\left[\operatorname{Dom}(\mathrm{f})=\right.$ man' $\left.\& \forall \mathrm{x}\left(\mathrm{x} \in \operatorname{Dom}(\mathrm{f}) \rightarrow \operatorname{meet}^{\prime}(\mathrm{f}(\mathrm{x}))(\mathrm{x})\right)\right]$

7. $\lambda \mathrm{f}\left[\operatorname{Dom}(\mathrm{f})=\right.$ man' $^{\prime} \& \forall \mathrm{x}\left(\mathrm{x} \in \operatorname{Dom}(\mathrm{f}) \rightarrow\right.$ woman' $^{\prime}(\mathrm{f}(\mathrm{x})) \&$

8. $\lambda F \sigma g[F(g)]$

meet' $(f(x))(x))]$

9. $\sigma g\left[\operatorname{Dom}(\mathrm{g})=\right.$ man' $^{\prime} \& \forall \mathrm{x}\left(\mathrm{x} \in \operatorname{Dom}(\mathrm{g}) \rightarrow\right.$ woman' $^{\prime}(\mathrm{g}(\mathrm{x})) \&$ meet' $(\mathrm{g}(\mathrm{x}))(\mathrm{x}))]$

9'. $\quad \lambda \mathrm{K} \exists \mathrm{f} \mid \mathrm{f}=\sigma \mathrm{g}\left[\operatorname{Dom}(\mathrm{g})=\right.$ man' $^{\prime} \forall \forall \mathrm{x}(\mathrm{x} \in \operatorname{Dom}(\mathrm{g}) \rightarrow$ woman' $(\mathrm{g}(\mathrm{x})) \&$ meet' $\left.\left.\left.^{\prime}(\mathrm{g}(\mathrm{x}))(\mathrm{x})\right)\right] \& \forall \mathrm{x}(\mathrm{x} \in \operatorname{Dom}(\mathrm{f}) \rightarrow \mathrm{K}(\mathrm{x})(\mathrm{f}))\right] \quad$ (by (40))

10. $\lambda \mathrm{x} \lambda \mathrm{f}\left[\right.$ invite' $\left.\left.^{\prime}(\mathrm{x})(\mathrm{f}(\mathrm{x}))\right)\right]$

11. $\exists \mathrm{flf}=\sigma \mathrm{g} \mid \operatorname{Dom}(\mathrm{g})=$ man' \& $\forall \mathrm{x}(\mathrm{x} \in \operatorname{Dom}(\mathrm{g}) \rightarrow$ woman' $(\mathrm{g}(\mathrm{x})) \&$ meet' $(\mathrm{g}(\mathrm{x}))(\mathrm{x}))] \& \forall \mathrm{x}\left(\mathrm{x} \in \operatorname{Dom}(\mathrm{f}) \rightarrow\right.$ invite' $\left.\left.^{\prime}(\mathrm{x})(\mathrm{f}(\mathrm{x}))\right)\right]$

"There is a function $f$ which is the unique/maximal function from men to the women they met, and for every $x$ in the domain of $f, f(x)$ invited $x$."

Let us briefly go through the derivation in (41) and (42): Node $\# 1$ is translated as the set of woman-valued functions. every man adjoins to the relative operator leaving behind a trace, which is co-indexed with the argument variable of the functional trace. Node $\# 2$ is interpreted as a relation between individuals and $<e, e>$-type functions. The unique minimal witness set of every man fixes the domain of the set of functions which the relative operator picks out. This set is intersected with the set of woman-valued functions. Applying functional the to the intersection of these two sets yields the unique function with the same property. 
Applying (40) to the translation of Node \#9, we get a set of relations from individuals to $<e, e>$-type functions.

Turning to Node \#10, we abstract over the function variable of the trace, and its argument variable (which is co-indexed with the pronoun), and we get a relation between individuals and $<\mathrm{e}, \mathrm{e}\rangle$-type functions. By feeding this translation into the translation of Node \#9, we get the expression in Line \#11. If (1) is true, then each man is paired with exactly one woman.

To sum up, in verbal sentences, the crucial steps which account for variable binding are: (a) Interpreting the relative clause as a set of functions with a specified domain; and (b) Interpreting the sister of the complex DP as a relation between individuals and $<e, e>$-type functions. (b) is licensed by the doubly-indexed trace of the complex DP. In equative copular sentences, the relative clause is interpreted as a set of contextually relevant "natural" functions, and (b) is not licensed.

\subsection{Indirect Binding in Copular Sentences}

In equative copular sentences, the subject of the relative clause undergoes standard $\mathrm{QR}$, and the relative clause is interpreted as a set of functions whose domain is not specified. The complex DP itself is interpreted as a unique "natural" function. I argue (with Jacobson (1994)), that in these cases it is asserted that two "natural" functions are the same.

One of the characteristics of a "natural" function is that its domain is determined by the context. For example, we may treat the function which maps students to their advisors as natural, as well as the function which maps children to their mothers, writers to their first books, etc. In RC's, the distinction between "natural" and "pair-list" functions is made by the two possible translations of the relative operator in (35). One of these translations yields a set of contextually relevant "natural" functions (represented by the free variable $\$$ ). If this translation is used in the interpretation of (2), then the structure and derivation of (2) are as in (43) and (44):

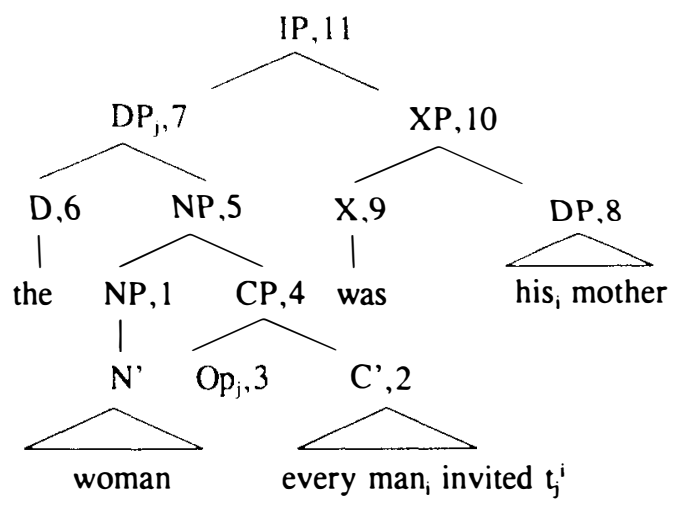




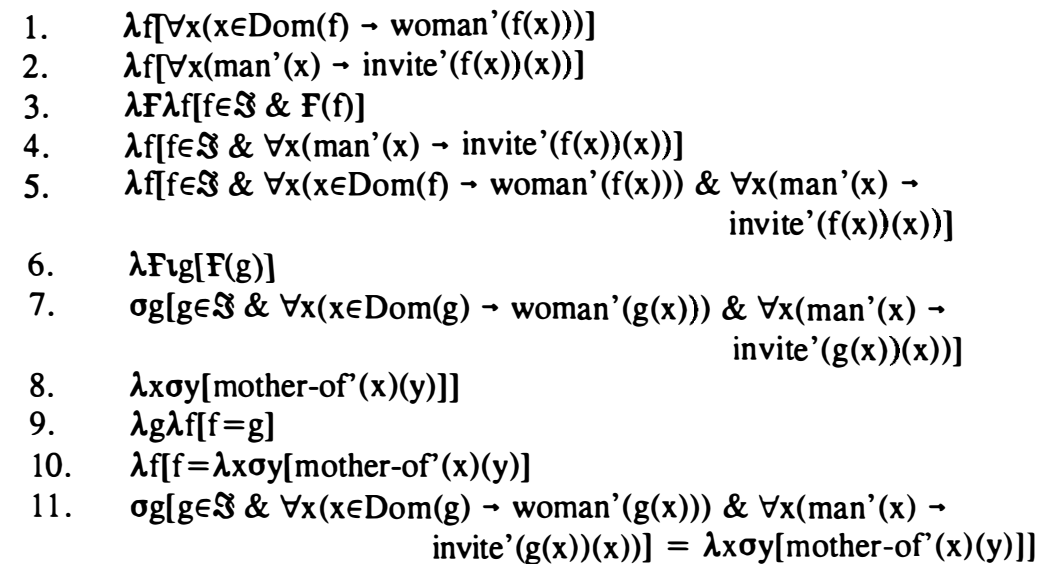

"The unique/maximal contextually relevant natural function which maps every man to the woman he invited is the 'mother-of' function."

In (43), the RC is interpreted as a set of contextually relevant "natural" functions $f$ such that for all $x$, if $x$ is a man, $x$ invited $f(x)$. This set is intersected with the set of woman-valued functions. Functional the picks out a unique/maximal function. In Node $\# 8$, we abstract over the variable denoted by his, and get a function from individuals to their mothers. Functional be equates the two functions. The domain of the 'mother-of' function is the set of individuals who have mothers. This is also the domain of the function denoted by the pre-copular DP.

Notice that plural relative heads (as in the women every man invited) are covered by the definition in (38) (both in verbal and copular contexts). In this case, for every $x$ in the domain of $f, f(x)=$ all the women that $x$ invited.

Notice also, that "natural" functions are excluded from verbal sentences, since according to the LF in (36b), the index of the quantifier in the RC does not percolate to the DP node. Consequently, if the DP is QR-ed, its trace is not doubly-indexed. This is a welcome result, since we do not want the subject DP in the woman every professor met invited him to be interpreted as a "natural" function with a domain larger than the set of professors. In a situation where every professor was invited by the woman he met, but some student was not invited by the relevant woman, the sentence would wrongly be judged as false. ${ }^{6}$

\section{Further Predictions}

\section{I Predicting the Range of Quantifiers allowed in the RC}

The assumption that in verbal RC's the domain of the function is the unique 
minimal witness set of the quantified expression which c-commands the trace of the relative opreator, allows only expressions which have unique minimal witness sets to fill that position. ${ }^{7}$ No-NP expressions are predicted to be ruled out since they have the empty set as their minimal witness set. Most-NP and few-NP are predicted to be ruled out because they do not have unique minimal witness sets. The same is true for almost-every-NP and almost-no-NP. In copular sentences, on the other hand, all these quantifiers are allowed. The following contrasts illustrate this:

\begin{tabular}{|c|c|c|c|c|c|c|c|}
\hline $\begin{array}{l}\text { ha-iSa } \\
\text { the-woman }\end{array}$ & & $\begin{array}{l}\text { af } \\
\text { no }\end{array}$ & $\begin{array}{l}\text { gever } \\
\text { man }\end{array}$ & $\begin{array}{l}\text { lo } \\
\text { neg }\end{array}$ & $\begin{array}{l}\text { hizmin } \\
\text { invite }\end{array}$ & $\begin{array}{l}\text { hayta } \\
\text { was }\end{array}$ & $\begin{array}{l}\text { iSt-o } \\
\text { wife-his }\end{array}$ \\
\hline \multicolumn{8}{|c|}{ 'The woman no man invited was his wife' } \\
\hline $\begin{array}{l}\text { ha-iSa } \\
\text { the-woman }\end{array}$ & $\begin{array}{l}\text { Se } \\
\text { that }\end{array}$ & $\begin{array}{l}\text { af } \\
\text { no }\end{array}$ & $\begin{array}{l}\text { gever } \\
\text { man }\end{array}$ & $\begin{array}{l}\text { lo } \\
\text { neg }\end{array}$ & $\begin{array}{l}\text { hizmin } \\
\text { invite }\end{array}$ & $\begin{array}{l}\text { nifge'a } \\
\text { get-hur }\end{array}$ & \\
\hline
\end{tabular}

\begin{tabular}{|c|c|c|c|c|c|c|}
\hline $\begin{array}{l}\text {-iSa } \\
\text { e-woman } \\
\text { a-iSa } \\
\text { e-woman }\end{array}$ & $\begin{array}{l}\mathrm{Se} \\
\text { that } \\
\mathrm{Se} \\
\text { that }\end{array}$ & $\begin{array}{l}\text { kim'at kol } \\
\text { almost every } \\
\text { kim'at kol } \\
\text { almost every }\end{array}$ & $\begin{array}{l}\text { gever } \\
\text { man } \\
\text { gever } \\
\text { man }\end{array}$ & $\begin{array}{l}\text { hizmin } \\
\text { invited } \\
\text { hizmin } \\
\text { invited }\end{array}$ & $\begin{array}{l}\text { hayta } \\
\text { was } \\
\text { hodeta } \\
\text { thanke }\end{array}$ & $\begin{array}{l}\text { im-o } \\
\text { mother- } \\
\text { lo } \\
\text { ed to-him }\end{array}$ \\
\hline $\begin{array}{l}\text {-iSa } \\
\text { e-woman } \\
\text {-iSa }\end{array}$ & $\begin{array}{l}\mathrm{Se} \\
\text { that } \\
\mathrm{Se}\end{array}$ & $\begin{array}{l}\text { rov } \\
\text { most } \\
\text { rov } \\
\text { most }\end{array}$ & & $\begin{array}{l}\text { pagSu } \\
\text { met } \\
\text { pagSu } \\
\text { met }\end{array}$ & $\begin{array}{l}\text { is } \\
\text { dibra } \\
\text { talked }\end{array}$ & $\begin{array}{l}\mathrm{m} \\
\text { their }\end{array}$ \\
\hline
\end{tabular}

(45) and (47) have a bound reading, while (46) and (48) do not. (49) also allows a bound reading easily, but (50) only has the non-bound ("single-individual") reading (where one woman talked to the men who invited her). The exclusion of most-NP and almost-every-NP from relative clauses in verbal sentences is predicted. What is surprising is that no-NP expressions are not always ruled out. Sentences such as the picture of himself which no candidate liked ruined his career, are judged as marginal by some speakers. However, even those speakers get a sharp contrast between these sentences and their copular counterparts, which are perfectly grammatical (e.g., the picture of himself which no candidate liked was the one which ruined his career). ${ }^{*}$ This contrast, and the contrasts in (45)-(50), support the claim that verbal sentences involve the same kind of functions as pairlist questions (where some quantified expressions are ruled out), and that copular sentences involve the same kind of functions as functional questions.

This claim is further supported by the fact that only copular sentences admit RC's with ATB (across-the-board) extraction, as shown by the following contrast:

(51) The picture of himself which every professor likes but every student hates is his driver's license photo. 
*The picture of himself which every professor likes but every student hates annoys his friends.

In (52), the domain of the function cannot be determined jointly by every professor and every student, since only one of them can adjoin to the relative operator. In (51), on the other hand, the domain of the function includes all the individuals with driver's licenses, and does not depend on the quantified expressions. Functional and pair-list questions contrast with each other in the same way.

\subsection{Uniqueness/maximality in Copular Sentences}

The claim that the domain of a "natural" function is not determined by the expression which binds the functional trace predicts some uniqueness effects which otherwise could not be predicted. For example, if the 'mother-of' function is defined for John, Bill, and John's mother, then (2) is judged as true in a situation where John and Bill invited their mothers, regardless of whether John's mother invited her mother or not. Since we predict only "natural" functions to be licensed in copular sentences, this result is guaranteed. We do not consider any function which is not "natural" in this context. For example, the function which maps John to his mother, Bill to his mother, and John's mother to herself, is a function which maps every man to the woman he invited, but it is not a "natural" function. On the other hand, if the domain of the function denoted by the pre-copular DP were the set of men, then in the situation described above, we could not claim that this function is the same as the 'mother-of' function.

For the very same reason, we predict the acceptability of (2) in a situation where some man or other invited another woman in addition to his mother (see sections 1 and 4.1). Suppose John invited Sally in addition to his mother. The function which maps John to Sally and every other man to his mother may or may not be a contextually relevant "natural" function. If it is not, then (2) is judged as true. On the other hand, we predict (1) to be unacceptable in a situation where some man met more than one woman.

In addition, as pointed out to me by Polly Jacobson, we predict a functional reading to be possible when both the pre-copular DP and the post copular DP contain functional dependencies, as in the following examples:

(53) The woman most men invited was the woman most men liked.

(54) The woman every student invited was the woman every professor liked.

(53) asserts that two "natural" functions are the same without naming them. It follows that both functions have the same domain. However, we cannot infer that the men referred to in the pre-copular DP are the same men referred to in the postcopular DP. For example, suppose that the set of men consists of John, Bill, Fred, and Paul. Suppose also that only John, Bill, and Fred invited their mothers, and 
that only Bill, Fred and Paul liked their mothers. The pre- and post-copular functions are the same, but the men who invited their mothers are not the same ones who liked their mothers (compare (53) with the woman most men invited was the woman they liked, where every man who invited a woman invited the woman he liked). (54) shows a similar effect.

\subsection{Predicting Clause-Boundedness}

In section 2 we discussed some scope problems which a $\mathrm{QR}$ analysis of Indirect Binding raises. One of the advantages of the functional analysis of Indirect Binding is that these problems do not come up. For example, The clause-boundedness effect in (13)-(14) is now predicted, because every man cannot be QR-ed beyond its clause. Likewise, the subject of the embedded clause is also QR-ed only locally. The functional trace created by this local QR licenses the interpretation of the IP as a relation of the right type to combine with the translation of the moved DP:

some woman $_{k}$ thinks that [[the picture of himself which every man hates $]_{j}^{i}$ [t ${ }_{j}^{i}$ will be given to her $\left.\left.{ }_{k}\right]\right]$

$$
\begin{aligned}
& \exists \mathrm{x}\left[\text { woman' } ^ { \prime } ( \mathrm { x } ) \& \text { think' } \left({ }^{\prime} \exists \mathrm{f} \mathrm{f}=\sigma \mathrm{g}\left[\operatorname{Dom}(\mathrm{g})=\text { man' }^{\prime} \& \forall \mathrm{z}(\mathrm{z} \in \operatorname{Dom}(\mathrm{g}) \rightarrow\right.\right.\right. \\
& \text { picture-of' }(\mathrm{z})(\mathrm{g}(\mathrm{z})) \& \text { hate' }(\mathrm{g}(\mathrm{z}))(\mathrm{z}))] \& \forall \mathrm{y}(\mathrm{y} \in \operatorname{Dom}(\mathrm{f}) \rightarrow \\
& \text { given-to' }(x)(f(y)))])(x)]
\end{aligned}
$$

This is the same clause-boundedness exhibited in (12), where there is no wide scope for every professor. Note, however, that if the complex DP occurs in the same clause as the indefinite, scope interaction is predicted by local QR (as in some student saw every professor):

eyzeSehu student makir et ha-ma'amar Se kol marce baxar some student knows ACC the-paper that every prof. chose

(58) a. [the paper that every prof chose $\left.t_{j}^{j}\right]_{j}^{\prime}$ [some student $]_{k}\left[t_{k}\right.$ knows $\left.t_{j}^{\prime}\right]$ b. $\quad \exists \mathrm{f} f \mathrm{f}=\mathrm{og}\left[\operatorname{Dom}(\mathrm{g})=\right.$ prof $^{\prime} \& \forall \mathrm{z}\left(\mathrm{z} \in \operatorname{Dom}(\mathrm{g}) \rightarrow \operatorname{paper}^{\prime}(\mathrm{g}(\mathrm{z})) \&\right.$ $\left.\left.\operatorname{chose}^{\prime}(\mathrm{g}(\mathrm{z}))(\mathrm{z})\right)\right] \& \forall \mathrm{x}\left(\mathrm{x} \in \operatorname{Dom}(\mathrm{f}) \rightarrow \exists \mathrm{y}\left(\mathrm{stu}^{\prime}(\mathrm{y}) \&\right.\right.$ know' $\left.\left.\left.^{\prime}(\mathrm{f}(\mathrm{x}))(\mathrm{y})\right)\right)\right]$

(59) a. [some student $\left.\right|_{k}$ [the paper that every prof chose $t_{j}^{i} l_{j}^{i}\left[t_{k}\right.$ knows $\left.t_{j}{ }^{\prime}\right]$

b. $\quad \exists y\left[s^{\prime} u^{\prime}(\mathrm{y}) \& \exists \mathrm{f}[\mathrm{f}=\sigma \mathrm{g} \mid \operatorname{Dom}(\mathrm{g})=\right.$ prof' $\& \forall \mathrm{z}(\mathrm{z} \in \operatorname{Dom}(\mathrm{g}) \rightarrow$ paper' $^{\prime}(\mathrm{g}(\mathrm{z}))$ \& chose' $\left.^{\prime}(\mathrm{g}(\mathrm{z}))(\mathrm{z})\right) \mid \& \forall \mathrm{x}\left(\mathrm{x} \in \operatorname{Dom}(\mathrm{f}) \rightarrow\right.$ know' $\left.\left.\left.^{\prime}(\mathrm{f}(\mathrm{x}))(\mathrm{y})\right)\right)\right]$

The problem raised by QR-ing decreasing quantifiers (see (19)) is solved in the same way: we interpret (19) as involving a functional dependency, and we do not QR no man beyond the clause it originates in: 
(60)

$$
\begin{aligned}
& \text { of }\left[\mathrm { f } \in \mathfrak { I } \& \forall \mathrm { x } ( \mathrm { x } \in \operatorname { D o m } ( \mathrm { f } ) \rightarrow \text { woman' } ^ { \prime } ( \mathrm { f } ( \mathrm { x } ) ) ) \& \forall \mathrm { x } \left(\operatorname{man}^{\prime}(\mathrm{x}) \rightarrow\right.\right. \\
& \neg \text { invite' }(\mathrm{f}(\mathrm{x}))(\mathrm{x}))]=\lambda \text { yox }[\text { mother-of' }(\mathrm{y})(\mathrm{x})]
\end{aligned}
$$

In this way we correctly predict a bound reading for (19), where negation has scope over the RC, and not over the matrix clause.

\section{Conclusion}

Indirect Binding is predicted to occur in DP's which contain functional dependencies. A DP of this sort is translated as a unique $\langle\mathrm{e}, \mathrm{e}\rangle$-type function. The subject/object asymmetry in RC's is analyzed as a WCO effect, and scope interactions are restricted in the desired way. The copular/verbal distinction is shown to parallel the functional/pair-list distinction in wh-questions.

\section{Endnotes}

*I am indebted to the following people for very helpful comments: Gidi Avrahami, Maria Bittner, Christine Brisson, Veneeta Dayal, Edit Doron, Pauline Jacobson, Roger Schwartzschild, and Arnim von Stechow.

'Throughout this paper, I use the term "copular sentences" to refer to equative copular sentences, and "verbal sentences" to refer to predicative copular sentences and non-copular sentences.

${ }^{2}$ See Jacobson (1994) and Bittner (to appear) for alternative functional approaches to WCO.

${ }^{3}$ See Dayal (1996) and Sharvit (in prep.) for evidence against May's $(1985,1988)$ PCC-based and ECP-based accounts of the subject/object asymmetry.

${ }^{4}$ According to Barwise \& Cooper (1981), a witness set is a subset of the common noun in a generalized quantifier, which is a member of the quantifier. A minimal witness set does not have subsets that are also witness sets.

${ }^{5}$ In point of fact, the operation which extracts a unique witness set is probably not free, and applies only to topics (Dayal (class lectures)).

${ }^{6}$ On the other hand, non-function be licenses a predicative reading of, say, (2).

${ }^{7}$ The use of unique minimal witness sets (Dayal (1996)), as opposed to minimal witness sets (Chierchia (1993)), gives a slightly different result for most, few and indefinites.

"The anaphor in the relative head may force a bound reading (see Sharvit (in prep.) for discussion). 


\section{References}

Barwise \& Cooper (1981). "Generalized Quantifiers in Natural Language", Linguistics and Philosophy 4,

Bittner, M. (to appear). "Functional Answers without Construction-Specific Rules", Linguistics and Philosophy.

Bittner, M. (1996). "Correlatives as Cross-categorial Descriptions". ms., Rutgers. Chierchia, G. (1991). "Functional WH and Weak Crossover", in D. Bates (ed.), Proceedings of WCCFL 10, CSLI, Stanford, California.

Chierchia, G. (1993). "Questions with Quantifers”, Natural Language Semantics 1.

Cooper, R. (1978). "Variable Binding and Relative Clauses," in F. Guenthner and S.J. Schmidt (eds.), Formal Semantics and Pragmatics for Natural Language, 131-169, D. Reidel Publishing Co., Dordrecht

Dahl, O. (1981). "Binding Relations in Dislocated Constituents", talk presented at the Sloan Workshop on Alternatives to Transformational Grammar, Stanford University.

Dayal, V. (1996). Locality in WH Quantification, Kluwer, Dordrecht.

Doron. E. (1982). "The Syntax and Semantics of Resumptive Pronouns", Texas Linguistic Forum 19, Dept. of Linguistics, Univresity of Texas, Austin.

Engdahl, E. (1986). Constituent Questions, Kluwer, Dordrecht.

Farkas, D. and A. Giannakidou (1996). "How clause-bounded is the Scope of Universals?" SALT VI.

Groenendijk, J. and M. Stokhof (1984). Studies on the Semantics of Questions and the Pragmatics of Answers, Academisch Proefschrift, Amsterdam.

Haïk, I. (1984). "Indirect Binding", Linguistic Inquiry 15/2

Hornstein, N. (1984). Logic as Grammar, MIT Press, Cambridge.

Jacobson, P. (1994). "Binding Connectivity in Copular Sentences", in M. Harvey and L. Santelmann (eds.), SALTIV.

Link, G. (1983). ."The Logical Analysis of Plurals and Mass Terms: A Latticetheoretical Approach", in R. Bäuerle, C. Schwarze \& A. Von Stechow (eds.), Meaning, Use and Interpretation of Language, De Guyter.

May, R. (1985). Logical Form, MIT Press, Cambridge, Massachusetts.

May, R. (1988). "Ambiguities of Quantification and WH: A Reply to Williams", Linguistic Inquiry 19.

Sharvit, Y. (1996). "Traces, pronouns, and Indirect Binding”, paper presented at the IATL 1996 workshop, Haifa, Israel.

Sharvit, Y. (in prep.) The Syntax and Semantics of Indirect Binding, PhD dissertation, Rutgers University.

Shlonsky, U. (1987). "Donkey Parasites", in J. McDonough and B. Plunkett (eds.), Proceedings of NELS 17, GLSA, University of Massachusetts, Amherst.

von Stechow, A. (1990). "Layered Traces", paper presented at the Conference on Logic and Language, Revfülüp, Hungary. 